\section{BMJ Open Respiratory Research}

\title{
Barriers to identifying occupational asthma among primary healthcare professionals: a qualitative study
}

\author{
Gareth I Walters (D) ,1,2 Christopher M Barber ${ }^{3}$
}

\begin{abstract}
To cite: Walters Gl, Barber CM. Barriers to identifying occupational asthma among primary healthcare professionals: a qualitative study. BMJ Open Resp Res 2021;8:e000938. doi:10.1136/ bmjresp-2021-000938
\end{abstract}

- Additional supplemental material is published online only. To view, please visit the journal online (http://dx.doi. org/10.1136/bmjresp-2021 000938).

Received 24 March 2021 Accepted 11 July 2021

Check for updates

(C) Author(s) (or their employer(s)) 2021. Re-use permitted under CC BY-NC. No commercial re-use. See rights and permissions. Published by BMJ.

${ }^{1}$ Regional NHS Occupational Lung Disease Service, University Hospitals Birmingham NHS Foundation Trust, Birmingham, UK ${ }^{2}$ Occupational and Environmental Medicine, University of Birmingham, Birmingham, UK ${ }^{3}$ Centre for Workplace Health, Northern General Hospital, Sheffield, UK

Correspondence to Dr Gareth I Walters; gareth.walters@ heartofengland.nhs.uk

\section{ABSTRACT}

Introduction 0ccupational asthma (OA) accounts for one in six cases of adult-onset asthma and is associated with a large societal cost. Many cases of $O A$ are missed or delayed, leading to ongoing exposure to the causative agent and avoidable lung function loss and poor employment-related outcomes. Enquiry about workrelated symptoms and the nature of work by healthcare professionals (HCPs) is limited, evident in primary and secondary care. Potential reasons cited for this are time pressure, lack of expertise and poor access to specialists. Aim To understand organisational factors and beliefs and behaviours among primary HCPs that may present barriers to identifying $\mathrm{OA}$.

Methods We employed a qualitative phenomenological methodology and undertook 20-45 min interviews with primary HCPs in West Midlands, UK. We used purposive and snowball sampling to include general practitioners (GPs) and practice nurses with a range of experience, from urban and rural settings. Interviews were recorded digitally and transcribed professionally for analysis. Data were coded by hand, and thematic analysis was undertaken and determined theoretically until themes were saturated. Results Eleven HCPs participated (eight GPs, three nurses). Four themes were identified that were considered to impact on identification of $\mathrm{OA}$ : (1) training and experience, (2) perceptions and beliefs, (3) systems constraints, and (4) variation in individual practice. OAspecific education had been inadequate at every stage of training and practice, and clinical exposure to $O A$ had been generally limited. OA-specific beliefs varied, as did clinical behaviour with working-age individuals with asthma. There was a focus on diagnosis and treatment rather than attributing causation. Identified issues regarding organisation of asthma care were time constraints, lack of continuity, referral pressure, use of guidelines and templates, and external targets.

Conclusion Organisation and delivery of primary asthma care, negative 0A-related beliefs, lack of formal education, and exposure to OA may all currently inhibit its identification.

\section{INTRODUCTION}

Occupational asthma (OA) is defined as asthma caused by inhalation of an agent encountered at work. Most cases occur following exposure to a respiratory sensitising agent, and a number of high-risk occupations

\section{Key messages}

Asthma care may not be organised in a way that supports attribution of an occupational cause.

- Primary healthcare professionals involved in delivering asthma care lack training and clinical experience in $\mathrm{OA}$ and display negative beliefs about its occurrence.

We have identified four themes that present barriers to identifying $O A$ in primary care and

- made recommendations for medical education and for clinical practice based on these findings.

are described (eg, bakers, paint sprayers). $\mathrm{OA}$ is relatively common among working-age individuals with asthma (population attributable fraction: $16 \%^{1}$ ), and despite regulatory activity in the UK aiming to prevent its occurrence the incidence has increased over the last 10 years, ${ }^{2}$ with novel agents frequently reported. ${ }^{3}$ Estimates suggest that OA costs the UK£1.1 billion each decade in terms of healthcare costs, job loss and state benefits. ${ }^{4}$ Early recognition of $\mathrm{OA}$, and removing the affected individual from the causative exposure, offer the best chance of a full recovery. ${ }^{5}$ UK asthma guidelines recommend that healthcare professionals (HCP) ask adults with new-onset or reactivated childhood asthma symptoms about the work-relatedness of their symptoms and the nature of their work, in order to screen for OA. ${ }^{6}$ OA should be excluded in those with work-related asthma symptoms, usually achieved via referral to a respiratory specialist with expertise in diagnosing OA (a handful of such specialists exist ${ }^{7}$ ).

In the UK, OA is under-reported to surveillance schemes ${ }^{8}$ and under-recognised by HCPs. This is evident in primary care, where the prevalence of clinician-diagnosed $\mathrm{OA}$ is much lower than expected among working-age individuals with asthma. ${ }^{9}{ }^{10}$ Furthermore, there are lengthy delays between symptom onset and diagnosis of OA (median 4 years), which may lead to adverse health and 
employment outcomes. ${ }^{11} 12$ Patients with OA lack awareness and understanding of the nature of work-related symptoms, and some are reluctant to seek help for fear of job or financial loss. ${ }^{13} 14$ Enquiry about the nature of work and work-related symptoms by primary HCPs is limited, and insufficient time, lack of expertise and poor access to specialist services have been cited as reasons for this. ${ }^{15-18}$ However, the factors that determine how HCPs behave when consulting working-age individuals with asthma, and the barriers to enquiry about work-related asthma symptoms, have not been studied in detail.

\section{Aim of the study}

The aim of this study was to explore and understand organisational factors and beliefs and behaviours among primary HCPs, which may present barriers to identifying OA in primary care.

\section{METHODS}

Reporting of study methods and results was undertaken according to the Standards for Reporting Qualitative Research. ${ }^{19}$

\section{Study design}

The study employed a phenomenological approach, in the interpretative tradition, using qualitative analysis of interviews with primary HCPs.

\section{Setting}

Interviews were undertaken with HCPs currently working at UK primary care practices in West Midlands, within 40 kilometres of the lead author's institution (radius chosen for convenience).

\section{Eligibility criteria}

Any practising, fully qualified general practitioner (GP) or practice nurse attending working-age patients with asthma was deemed eligible for the study. All participants were required to speak English during their interview.

\section{Sample selection}

Purposive sampling was undertaken, targeting GPs and practice nurses from urban and rural settings who were likely to have a range of experience with working-age individuals with asthma during their training and practice. Further snowball sampling of professional acquaintances was also undertaken, by asking participants identified via educational seminars to recommend colleagues.

\section{Participant recruitment}

The number of participants was determined by saturation of themes, although it was expected to be less than 15 , since a small number has previously been deemed adequate for narrow research questions. ${ }^{20}$ The primary author had delivered free educational seminars on workrelated lung disease, specifically for primary HCPs, since 2015; during seminars undertaken in late 2018, attendees were given an email address to contact if they were interested in participating in the study. Inducements of $£ 75$ were offered to any HCP attempting the interview, except for participant 1. Participant 1 was the wife of the lead author and her interview was undertaken as a pilot, in order to check audio and comprehension of question phrasing. Preinterview, there was no intention to include its data, although once completed the authors felt that it yielded data worthy of inclusion in the analysis. Participant 1 highlighted the study among professionals (participants 2 and 3 ) from the same practice group, who were subsequently included. Additionally, participants 8, 9 and 10 were snowball-sampled from the same practice as participant 6 .

\section{Data collection}

All interviews were undertaken face to face by the primary author at participants' homes or places of work; written informed consent was sought preinterview. Interviews lasted between 20 and $45 \mathrm{~min}$ and were conducted according to a semistructured schedule written by the primary author, based on his clinical experience, with previously published data in mind (online supplemental file 1). All interviews were audio-recorded using a handheld digital Dictaphone; no file notes were taken.

\section{Data transcription}

Digital audio files were transcribed by a professional typist. Standard UK written English was used and common abbreviations preagreed. The actual words used (including acronyms, abbreviations, slang, aborted sentences) were transcribed, but since conversation analysis was deemed less important in this study, other nuances of talk were not included (eg, non-verbal features, intonations, stutters). Social conversation before and after each interview was not transcribed.

\section{Thematic analysis}

The interview transcriptions were analysed by the primary author, with coinvestigator $\mathrm{CMB}$ acting as a critical friend. ${ }^{21} 22$ Open coding was undertaken (no pre-existing codes, developed and modified throughout coding process). ${ }^{23} 24$ Analysis was predominantly theoretical, answering the research question, rather than inductive. A preliminary analysis was undertaken by the primary author after seven interviews, and domains that required further enquiry were highlighted. Further interviews were undertaken aiming for saturation of themes.

\section{Reflexivity}

The interviewer (GIW) was a 43-year-old, male, white British National Health Service (NHS) consultant physician with a specialist interest in OA. He was trained in 
Table 1 Summary of participant healthcare professionals undertaking semistructured interviews with the researcher

\begin{tabular}{|c|c|c|c|c|c|}
\hline Participant & Gender & Job title & $\begin{array}{l}\text { Formal respiratory or } \\
\text { occupational health role? }\end{array}$ & $\begin{array}{l}\text { Years of } \\
\text { experience in } \\
\text { primary care }\end{array}$ & $\begin{array}{l}\text { Location of } \\
\text { practice }\end{array}$ \\
\hline 1 & Female & Salaried GP & No & 4 & City centre \\
\hline 2 & Female & GP partner & No & 28 & City centre \\
\hline 3 & Male & GP partner & $\begin{array}{l}\text { Current practice respiratory } \\
\text { lead }\end{array}$ & 14 & City centre \\
\hline 4 & Male & GP partner & $\begin{array}{l}\text { Previous GPSI in COPD for } \\
5 \text { years }\end{array}$ & 20 & City suburb \\
\hline 5 & Female & Practice nurse & No & 30 & MOD site \\
\hline 6 & Female & Practice nurse & No & 23 & City suburb \\
\hline 7 & Male & GP partner & No & 4 & Semirural \\
\hline 8 & Female & GP partner & No & 7 & City suburb \\
\hline 9 & Female & GP partner & No & 20 & City suburb \\
\hline 10 & Female & Practice nurse & No & 15 & City suburb \\
\hline 11 & Male & GP partner & Current practice asthma lead & 34 & Semirural \\
\hline
\end{tabular}

COPD, chronic obstructive pulmonary disease; GP, general practitioner; GPSI, GP with a specialist interest; MOD, Ministry of Defence.

hospital medicine in the late 1990s-early 2000s and had no personal experience of working in primary care. GIW had preconceived ideas about the cause of poor or delayed identification, through his own training, clinical observations and previous research undertaken; he was potentially unknowing of many organisational aspects of primary care at the time the study was undertaken.

\section{RESULTS}

Descriptive analysis

Eleven HCPs participated in the study (summarised in table 1), comprising four female and four male GPs (median experience 17 years) and three practice nurses (median experience 23 years). Of the six individuals who made contact following a seminar, all consented and became participants.

\section{Qualitative analysis}

Four themes impacting on whether HCPs were likely to suspect and investigate patients for OA were identified: (1) training and experience, (2) perceptions and beliefs, (3) systems constraints, and (4) variation in individual practice (summarised in table 2 ).

\section{Theme 1: training and experience}

Six out of eight GPs described little or no formal exposure to OA during undergraduate or postgraduate study. Three GPs recognised that occupational respiratory disease featured during their undergraduate study, although the focus was not $\mathrm{OA}$ (eg, pneumoconiosis, mesothelioma). Eight GPs gained continuous professional development (CPD) by attendance at a short general topic update course, which included asthma management; two GPs recalled that OA was mentioned, although stressed that the emphasis was on diagnosis of asthma and its treatment. Two nurses described having little formal training in asthma management, with no emphasis on OA, since beginning their professional roles.

(re: undergraduate education) I can just imagine it was like one lecture with a table or something that you probably learn for an exam and never refer to again, and it didn't feel like it's an inherent part of your assessment of respiratory disease. (P3)

In current roles, three GPs had no experience of OA at all and five GPs or nurses described some limited experience. Three GPs suggested that their experiential learning in asthma depended on previous job specialty, content of training rotations, and expertise and interests of trainers and colleagues. Three HCPs cited personal or family experiences as influences on their current understanding of asthma and OA. All participants noted that primary care had changed to include specialist areas of practice, with nurses, nurse practitioners and dedicated GPs taking on greater responsibilities for chronic respiratory disease diagnosis and management (see online supplemental file 2).

Well we've seen people who you can see there's a correlation there, they seemed to have never had a problem and suddenly they're struggling, and there is definite link there. So yeah, I can't think I've seen lots of people, but I've probably seen a handful of people like that. (P3)

And all of us have had other influences. Because I have to admit, my asthma management is influenced by our eldest, who had asthma reasonably badly as a child and they grow out of it. So I find that my individual experience of how people deal with it almost informs me. (P2) 


\section{Table 2 Summary of themes, subthemes and codes derived from analysis of interviews with GPs and practice nurses}

\begin{tabular}{ll}
\hline Theme & Subtheme \\
\hline $\begin{array}{l}\text { 1. Training and } \\
\text { experience }\end{array}$ & $\begin{array}{l}\text { Limited feature } \\
\text { in undergraduate } \\
\text { education. } \\
\text { Limited feature in } \\
\text { formal postgraduate } \\
\text { education. }\end{array}$ \\
& \\
& $\begin{array}{l}\text { Limited feature of } \\
\text { experiential ('on-the- } \\
\text { job') learning. }\end{array}$ \\
& \\
& \\
& $\begin{array}{l}\text { Primary care asthma } \\
\text { diagnosis and } \\
\text { management have } \\
\text { become a more } \\
\text { specialised task. }\end{array}$
\end{tabular}

\section{Codes}

Little formal medical school exposure to OA.

Focus on other occupational or exposure-related aspects of respiratory disease.

Not a formal part of GP vocational training.

Little focus on OA in asthma-related CPD.

Little formal training on asthma management for practice nurses.

Likely only to do asthma-related CPD if in a respiratory role.

$\mathrm{OA}$ a feature of experiential learning.

OA not a feature of experiential learning.

Exposure to specific disease areas varies between individuals during formative experiences.

Personal experiences have influenced practice more than any experiential learning.

Some GPs take on the responsibility for management of respiratory diseases within the practice.

Some GPs have become deskilled at asthma management.

Some GPs see individuals with asthma only in certain circumstances.

Increased GP workload has resulted in practice nurses taking on more asthma management.

Some practice nurses are the respiratory experts within practices.

Individuals with asthma receive chronic disease management in specialised clinics, primarily delivered by practice nurses and nurse practitioners.

\section{Perceptions and} beliefs
Variation in subject knowledge.
Beliefs about the occurrence of OA.
Appreciation of factors in the clinical presentation suggestive of OA.

GPs lack knowledge about OA.

OA perceived to be a specialist subject.

Unable to relate learnt enquiry about exposures (eg, birds, chemicals) to OA.

Variation in understanding of high-risk exposures for $O A$.

Different ideas about the impact of OA on individuals and collectively.

Work-related symptoms are trivial.

Work exposures trigger, not cause, asthma in susceptible individuals.

Onset of asthma in adult life is not unusual.

$\mathrm{OA}$ is not prevalent in the local patient population.

$\mathrm{OA}$ is underestimated in primary care.

$\mathrm{OA}$ is a historical problem.

Perceived risks and Jeopardy for patients' jobs and income if investigated further.

benefits of making a Potential health and employment benefits for affected patients.

diagnosis of $\mathrm{OA}$.

Specialist care adds value in diagnosing and managing $\mathrm{OA}$.

Complex and challenging diagnostic process for OA.

Workplace management requires specialist knowledge.

Central coordination of cases is important in identifying outbreaks of OA or novel causes.

Beliefs about the role Responsibilities for diagnosis and management of OA lie outside the NHS. of primary care in diagnosing OA.
Shared responsibilities between primary and specialist care.

Certain level of knowledge should be attained in primary care. 
Table 2 Continued

\begin{tabular}{|c|c|c|}
\hline Theme & Subtheme & Codes \\
\hline \multirow[t]{14}{*}{ 3. Systems constraints } & \multirow{3}{*}{$\begin{array}{l}\text { Lack of continuity of } \\
\text { care. }\end{array}$} & Patients are looking for a quick fix. \\
\hline & & Less opportunity to explore social aspects of health. \\
\hline & & Poor continuity of HCPs between consultations. \\
\hline & \multirow{2}{*}{$\begin{array}{l}\text { Time pressure and } \\
\text { workload. }\end{array}$} & Priority is to make a diagnosis of asthma. \\
\hline & & Lack time for detailed enquiry and diagnosis of $\mathrm{OA}$. \\
\hline & \multirow[t]{3}{*}{ Use of guidelines. } & No OA-specific guidelines used. \\
\hline & & Use of asthma guidelines varies between individuals and practices. \\
\hline & & Clinic templates do not focus on OA. \\
\hline & \multirow[t]{3}{*}{ External targets. } & Practice driven by essential requirements only. \\
\hline & & Focus on diagnosis and drug management of asthma. \\
\hline & & Perceived as a tick-box exercise. \\
\hline & \multirow[t]{3}{*}{ Referral pressures. } & Perceived restrictions on referrals. \\
\hline & & $\begin{array}{l}\text { Diagnosis and management of OA would be an 'acceptable' reason to refer to } \\
\text { a specialist. }\end{array}$ \\
\hline & & Feel a pressure to reduce unnecessary referrals. \\
\hline \multirow{7}{*}{$\begin{array}{l}\text { 4. Variation in individual } \\
\text { practice }\end{array}$} & \multirow{3}{*}{$\begin{array}{l}\text { Variation in clinical } \\
\text { enquiry about work } \\
\text { and OA. }\end{array}$} & Enquire about work-related asthma symptoms or not. \\
\hline & & Enquire about occupation and nature of work or not. \\
\hline & & Would not revisit the cause if diagnosis of asthma already made. \\
\hline & \multirow{2}{*}{$\begin{array}{l}\text { Different thresholds } \\
\text { or referral to a } \\
\text { specialist. }\end{array}$} & Would refer on suggestive history for OA alone. \\
\hline & & Would not refer on suggestive history for OA alone. \\
\hline & \multirow[t]{2}{*}{ Referral preferences. } & Would refer to local secondary care physicians. \\
\hline & & Perceived difficulty in accessing occupational lung \\
\hline
\end{tabular}

CPD, continuous professional development; GP, general practitioner; HCP, healthcare professional; NHS, National Health Service; OA, occupational asthma.

\section{Theme 2: perceptions and beliefs}

Four GPs stated that they lacked OA subject knowledge, and one perceived OA to be a specialist subject, out of scope for general practice. Four GPs found it difficult to contextualise information gathered about exposures. Two GPs believed knowledge work and office environments carried no risk for OA.

I don't know if GPs would have any knowledge of what it might be that's causing their asthma... Very occasionally, they'll [patients] come with a leaflet of all the chemicals they use but I don't understand that any more than they do...that's one of the reasons we are GPs because we don't want to deal with something in great detail day in and day out. That's not the sort of people we are. (P4)

And you know, you start on the wards and you've got your list of questions, systems review stuff isn't it, and pets and pigeons and all that kind of stuff... it felt irrelevant at the time. But it was on your list so you just blindly ask it without perhaps thinking 'Why am I asking these questions?' (P3)

Beliefs about the occurrence of $\mathrm{OA}$ are detailed in table 3; many of these imply that OA has little impact on society, locality or on individual practice. However, seven
HCPs recognised health and employment benefits for affected individuals, comprising certainty and clarity of diagnosis, validation of symptoms and ill health, symptom and functional improvements, and retention of employment and income. Workforce and public health benefits were also cited: identifying novel causes, controlling local outbreaks and avoiding similar harms to other workers. Eight HCPs saw jeopardy in making a diagnosis of OA, including inducing fear of and actual job loss, difficulty finding alternative, unexposed skilled work, and false diagnoses leading to avoidable job loss. The majority of HCPs believed that involving specialists (either respiratory or occupational health) added value over primary care, in terms of complexity of diagnosis, time resource required, interpretation of tests and managing the workplace aspects. Opinions varied on where the responsibility for identifying OA lay and the role of primary care:

Our job is just to point people in the right direction. I think the idea that GPs are going to make these diagnoses and have the knowledge to know what to do with it... it is complex stuff, isn't it? (P4)

If you define what it is and you can somehow avoid the trigger and therefore everything is fine and you can just do your standard sort of approach to 
Table 3 Beliefs about the occurrence of OA

\section{Code \\ Different ideas about} the impact of $O A$ on individuals and collectively.

Work-related symptoms are trivial.

Work exposures trigger, not cause, asthma in susceptible individuals.

\section{Examples}

"And when we've suspected It [OA], it doesn't feel like it's having a massive impact on patient's lives. They sort of seem to kind of say 'Oh yeah, I feel a bit wheezy there, but I'm alright when I get home.'” (P3)

"I don't see lots of people saying, 'My occupational asthma is ruining my life.' In that regard, it's not high up the list of things we worry about. We probably miss a lot of it. Everyone is exposed to all the particulates that around here because we're in the middle of the inner city and a mile away from an incinerator. I guess that's more relevant. Around here, a lot of our patients have hard lives. If you said to my colleagues, 'Give us a list of your Top 10 things you're worried about,' occupational asthma would not be on it." (P4)

"There's no doubt I'm sure it is very significant to somebody who has got it, and it's got to have a societal impact if it's stopping people working, especially those in skilled jobs, who we need doing those jobs. If they can't work then that's clearly got a societal impact." (P1)

"But I think it is important though, it is certainly important because it affects a person in their prime when they can work and it is going to impact on their living and day to day activities. They can't even offer to take time off to come and see the GPs, you know, to get appointments so it certainly has." (P8)

"The only thing would be, occasionally, patients, will say you know 'Since l've worked in that factory, I don't like the smell of the paint' or that sort of thing... But I have to say, I've never taken it very seriously if people say things like that." (P2)

"One of the problems actually is I think my belief is that you are kind of born with a susceptibility to it [asthma], we can all be pushed to wheeze if we're pushed far enough; but that your tendency to wheeze is sort of what you're born with, and it's sort of an endogenous thing, and not to do with what you're exposed to in the future." (P2)

"I've always been sort of historically [sic] you've had a tendency and that's the trigger. But in terms of it actually bringing it all on, I've never really thought about that, no. I guess you can get sensitised to stuff and presumably react and whatever." (P3)

Onset of asthma in adult "I don't think that's a prevalent view amongst GPs [that adult-onset asthma is unusual]. It's a bit like life is not unusual. if someone comes in with hypertension, you don't necessarily go back to saying, 'Have you really got hypertension?'“ (P4)

"We were always told asthma could come on at any time at any time of life and not that it was unusual. It's made me think more about when it is adult asthma we should be looking more into occupation." (P6)

$\mathrm{OA}$ is not prevalent in the "I don't know how many cases that might be occupational we would have in our registered local patient population. population, but presumably none of us are seeing that many of them. I don't think the area that we are in, there isn't much industry which would be relevant." (P1)

"A lot of our patients don't work. They might be working age but a lot of them aren't actually employed... Even a practice this size, l'd be surprised if we have 20 patients for whom occupational asthma is their main diagnosis. That's as rare as all the kids we've got with genetic disease." (P4) "This is rare stuff for us I would say. One in 6 [occurrence of OA amongst asthmatics] was a surprise, I would've said if it was 1 in 6 in our population we'll be missing a lot. Yeah, it's a rare diagnosis. That's hard though because it is rarer in our environment because we haven't got a lot of people that work in industry as such, or we're missing a lot." (P11)

$\mathrm{OA}$ is underestimated in "I think it seems to be very underestimated. You hear a lot about smoking and the impact that not primary care. smoking in public places has done and actually it's things like people not wearing masks in various jobs that they do." (P7)

"Well I know the statistics are slightly that GPs undermanage existing asthma, and there's a lot of talk that we over-diagnose, but we also under-diagnose. So we're not very good at screening out the right people. And I know there's been a lot of fuss about that recently. So that makes me think do we do under-diagnose, so maybe there are people out there that we haven't really sort of sorted out... But if you ask me is it occupational, well now l'm beginning to think 'What am I missing?' But I would've just thought 'Oh, it's asthma'. I wouldn't attribute it to triggers very often." (P2) 


\section{Table 3 Continued}

\begin{tabular}{|c|c|}
\hline Code & Examples \\
\hline $\begin{array}{l}\text { OA is a historical } \\
\text { problem or associated } \\
\text { with traditional industry. }\end{array}$ & $\begin{array}{l}\text { "I do think of it as a slightly historical thing, as we were saying, because you think surely in this } \\
\text { day and age health and safety, you wouldn't be allowed to do it if it was that dangerous. But you } \\
\text { certainly come across people working long hours or doing repetitive things and they get muscular } \\
\text { skeletal conditions, people stressed by poor management. So actually, there is quite a lot of work- } \\
\text { related stuff, but in terms of respiratory, the only things that I can think of causing a problem are } \\
\text { more an allergy. I was thinking farmers, farm workers... I think of occupational respiratory problems } \\
\text { as the asbestosis and coal mining, those sorts of things. So, it barely enters my consciousness } \\
\text { really." (P2) } \\
\text { "I'd be more surprised if someone pitched up and said, 'I'm in a cabinet with no mask and they're } \\
\text { pumping this gas through.' Whereas } 20 \text { years ago, that was probably commonplace, I guess." (P4) }\end{array}$ \\
\hline
\end{tabular}

GP, general practitioner; OA, occupational asthma.

treatment and everything seems stable, then yeah, I think it's fine to absorb that in general practice. (P3)

I'm assuming there is legislation around occupational asthma and hazards... So, I'd kind of feel like I was out of my depth. And I suppose that's where I'd see the shared care bit really, is the occupational team looking after that and the general health with me. (P7)

\section{Theme 3: systems constraints}

A number of issues were identified around the organisation of services, either nationally or locally, generically or specific to asthma care.

\section{Lack of continuity}

One GP suggested that patients were no longer interested in durable doctor-patient relationships. One GP reflected on a progressively 'shallower' understanding of her patients' lives due to time pressure. One GP reported that the combination of short appointment times and lack of continuity between HCPs had led to repetition of enquiry and investigation, which would impede attributing causation for asthma.

\section{Time pressure}

Nine HCPs cited time pressure as a barrier to recognising $\mathrm{OA}$, with many prioritising asthma diagnosis and medical treatment over cause attribution. Two described the experience as 'inadequate' or 'feeling like survival'.

That's why I don't now work for the NHS because I refuse to do an inadequate job and the time given is inadequate and it doesn't allow you to do things properly. (P5)

However one GP disagreed somewhat:

Yeah, our days are longer, but I don't think I'm less likely to make that diagnosis because I'm so time poor with the patient any more than I used to be. (P11)

\section{Guidelines and clinic templates}

There was no knowledge or use of OA-specific guidelines among HCPs, but four HCPs recalled sections on $\mathrm{OA}$ in generic asthma guidelines. Some suggested that use of asthma-related guidelines varied between practices and/or individuals, and any protocols were subject to external influences, such as area prescribing committees, or locally commissioned asthma care standards. Four GPs described using clinic templates designed locally or adapted from published templates, although made no reference to OA or work.

And I know certainly on whatever template we've got, there isn't a question about work, what is work or are your symptoms worse at work, which probably we do need to think about doing that. I wonder if maybe that could be some of the mismatch between us seeing it, it not ending up in secondary care. (P3)

\section{External targets}

The national quality programme for primary care, the Quality Outcomes Framework ('QOF'), was identified by almost all HCPs as the major influence on organisation and delivery of primary care asthma services, and in turn how and which data were captured: exclusively electronically, usually via a template, and with a focus on data essential for QOF (asthma control questionnaires, treatment strategy); however, on occasion, there appeared to be local variation in QOF requirement. For some HCPs this was perceived as a 'tick-box' exercise or incomeoriented, and not individual patient outcome-centred.

We'll go through the proforma, look at their symptoms and do their Asthma Control Test, and if it all seems okay, we'll say, 'Right, carry on'. There's no incentive to make a diagnosis of occupational asthma. (P4)

You are driven in part by what QOF requires you to do and it might have a template with multiple boxes on it and one of those could well be 'Did you ask about occupational asthma?'. But if it's not QOF-able 
and the patient's saying 'I'm fine, doctor', I'm not touching that. (P11)

\section{External pressures on referral}

There was consensus among all seven HCPs who commented that referring a case of suspected OA to a specialist would be 'reasonable', defined variously in terms of rarity of disease, complexity of investigation and management; that is, the referral added 'value' over primary care, but was also acceptable under scrutiny from colleagues or other agencies. Most HCPs perceived pressure on their referral practice; some, not all, had referrals 'monitored' within the practice or clinical commissioning group (CCG) and were keen to avoid referrals deemed unnecessary (ie, specialist unlikely to add value), or appearing to have too low an index of suspicion for diagnosis, and being an outlier within the practice (more referrals than their colleagues) or CCG (more referrals than average).

I think we all feel under pressure to reduce referrals, because we are under pressure to reduce referrals. So, we now have a referrals MDT every week, and we look for ways that we can perhaps manage the patient within the practice, or avoid an unnecessary referral ... All of our thresholds for referring anything that is not suspected cancer has had to go up. (P1)

\section{Theme 4: variation in individual practice} Clinical enquiry

Of 11 HCPs who commented on their own clinical enquiry, 5 would unconditionally ask individuals with asthma about work-related symptoms, 4 conditionally (uncontrolled or new adult-onset symptoms, in a highrisk job) and 2 not at all. Seven HCPs commented on enquiry about occupation and the nature of work: four would ask unconditionally, two would not routinely ask, and one conditionally, only in the context of new-onset asthma. Two GPs described a tendency not to revisit the cause once a diagnosis of asthma had been made.

It's not something that I've really thought about before if I'm honest. I tend to focus on the house, like is it dusty, have you got a cat, have you got dogs, have you got birds? Not so much the job. I've not come across it because I wouldn't normally ask. (P10) I wouldn't say that I'm proactively asking questions but what I do find is that patients are quite well aware when there is something that triggers their problems. They do figure it out usually and they will tell you. (P9)

\section{Referral thresholds}

Of six GPs that commented, three would make a referral based on a suggestive medical history only, and three would want further investigations first (peak flow measurements). Qualities of a good referral were cited as: tests or opinion required but unavailable in primary care, a positive diagnosis of OA likely, meets specialist's (presumed) expectation that 'basic' tests had already been carried out.

I think the idea of doing occupational peak flows and all the rest of it... we don't have the wear-withall to do it, to be honest, or the time to explain to the patient. We have seven [minutes]... our job is to be more aware and screen for the patients and then refer on, I guess. (P4)

You know, you don't want to be too quick on the trigger on referral... We've been brought up with the 'history, examination, investigation' model, and I think you are duty-bound as the GP to try your best to put it on a plate for the consultant. (P11)

\section{Referral practice}

Three of four HCPs that commented were unaware of any regional referral centre for occupational lung diseases, and one believed that they would be unable to refer directly, needing to send patient to a local respiratory service first. Eight HCPs reflected on their own referral practice, which in all cases would be to refer a patient with suspected $\mathrm{OA}$ to a local secondary care provider first. Three HCPs mentioned that they might access their local electronic 'Advice and Guidance' service.

We just do it electronically now. There is a slight frustration because it is quite difficult sometimes to pick your consultant of choice. If I wanted you [interviewer], particularly, to see the patient, it's not that easy. (P4)

\section{DISCUSSION}

\section{Limitations and generalisability}

Four distinct themes were identified, although others unknown to the researchers due to their background in hospital medicine, and not considered by the interviewees, could have been missed. Only one salaried GP was included and no doctors-in-training, who may have had a different perspective on training, although the range of experience of GPs was in fact broad (4-34 years). The study was sufficient to highlight the effect of differences in experience and training among GPs, although all routes through GP training are unlikely to have been accounted for, given the limited sample size. The small number of practices included and their geographical location (West Midlands) may also limit generalisability of findings, relating to training and local operating procedures. Many participants may be considered enthusiasts, having attended an evening symposium on OA, leading to selection bias (although there are in fact many reasons why HCPs do so). There was also therefore some preconditioning on the subject of interest, although most participants qualified their thoughts and behaviours as relating to presymposium (no explicit direction on this had been given before the interview). In order to increase truthfulness, thematic analysis was undertaken with a critical 
friend $(\mathrm{CMB})$ and an audit trail was created for coding and organisation of themes. Interviews were undertaken at participants' convenience, and they were encouraged to talk truthfully and openly, although ultimately some may have been reluctant to talk about aspects of their individual practice, if they perceived these to be different from others or 'wrong'. Generally, however, these were felt to be generous and truthful accounts.

\section{Training and experience}

There was little focus on OA, or indeed on occupational health aspects of disease, evident during formal periods of training. Descriptive knowledge learnt tended to relate to asbestos, coal dust or non-specific pollutants (eg, dust, fumes), and not agents or jobs specific to OA; many GPs were unclear what to do with information gathered about occupational exposures, in the context of asthma. Process-oriented targets for asthma, and CPD seemingly aligned to these, are currently focused on objective diagnosis, establishing treatment and good asthma control (all worthwhile goals per se), but have deprioritised finding a cause. From the medical literature, physicians self-report low awareness of OA and lack OA-specific education, and cite complexity (too many causes, detailed occupational history required) as a barrier to diagnosis. ${ }^{1725}$ Thus, in acute hospital and primary care there is little clinical enquiry about $\mathrm{OA}$, and opportunities to detect $\mathrm{OA}$ are missed ${ }^{26-28}$ An evidence-based e-learning module on OA can increase knowledge and use of guidelines among primary HCPs. ${ }^{15}$

\section{Individual beliefs and practice}

Many negative beliefs about the occurrence of OA and its social impact were evident and are likely to inhibit clinical enquiry. Parhar $e t a l^{17}$ reported two factors leading physicians to attribute asthma to work: other work colleagues are affected, or the physician had previously attended a case due to the same causative agent. The perception of low prevalence of OA may be self-fulfilling since a missed diagnosis may not subsequently be recognised at all. The societal burden of OA is in fact high, ${ }^{4}$ and the incidence has not decreased since new causes and 'at-risk' industries emerge, as others disappear. ${ }^{2}$

Referral practice was predisposed by individual beliefs about the worth of a referral, that is, whether it reached thresholds of 'acceptability' and 'quality' described earlier, in part influenced by external pressures. However, all participants that commented saw advantages for specialist referral of suspected OA, due to the complexity and uncertainty of both diagnosis and management. Most HCPs would refer cases to a local secondary care physician, either through unawareness of an NHS occupational lung disease service (which may be a local phenomenon) or because local policy dictated so. A model explaining the variation in individual behaviour and potential barriers to identifying $\mathrm{OA}$ is shown in figure 1 .

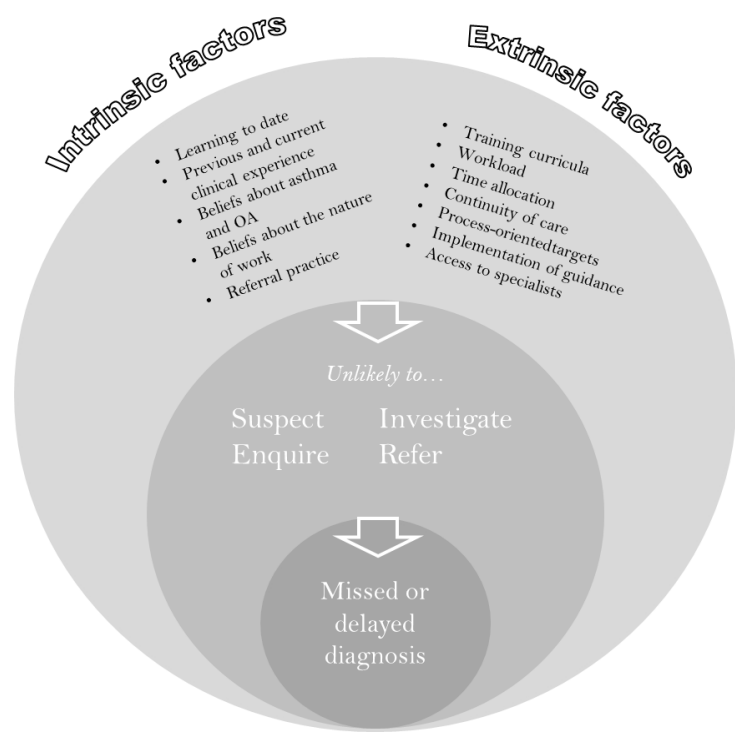

Figure 1 A conceptual model describing extrinsic factors and individual healthcare professional-oriented influences on missed or delayed diagnoses of occupational asthma (OA).

\section{Systems constraints}

There were a number of negative extrinsic influences on practice, specifically: lack of continuity of care, time pressure and increased GP workload, external targets, referral pressures, and lack of guideline use. The result has been that identifying an occupational case for asthma is a low priority for primary HCPs, who are not incentivised to do so. Some HCPs felt that lack of continuity, time and increased workload meant that they were unable to know their patients' lives in detail as they used to, to the detriment of holistic care. MacKinnon et $a l^{25}$ suggested that lack of systematic screening for OA in primary care contributes to delayed diagnosis, although acknowledged that the optimal screening tool is currently unknown. Others have previously cited time constraints and lack of access to specialists as barriers to diagnosis. ${ }^{17} 18$

\section{CONCLUSION}

Although specific guidelines are published relating to identification and referral of suspected $\mathrm{OA}^{6}{ }^{6}{ }^{11}$ there are limitations to the current model for primary asthma care that inhibit recognition and onward referral to a specialist. Additionally, lack of provision of formal education at each stage of training and variation in clinical experience are likely to influence disease-specific beliefs for HCPs, and inhibit further action in at least some cases. Recommendations for education and clinical practice are considered in table 4 . Whether screening individuals with asthma in primary care for OA is helpful, and the optimal tool for doing so, are both currently unknown and require evaluation.

Contributors GIW undertook the study design, interviews and data analysis, with CMB acting as a critical friend. Both authors wrote and edited the manuscript. 
Table 4 Recommendations for healthcare education and clinical practice

Education Broadly, understand cause and effect with respect to occupational disease and the effect of work on health; address these at all stages of training.

Appreciate the value of knowing about occupational and environmental exposures in respiratory disease, particularly why it may be beneficial to attribute causation to work, in terms of health and employment outcomes for workers. Contextualise the declarative knowledge of individual causes or relevant occupational exposures.

Challenge perceptions that OA is a 'historical' disease by teaching about novel causes and novel and prevalent exposures and surveillance systems.

Highlight the benefit of early diagnosis and referral to a specialist (where indicated) in terms of health and employment outcome; have a low threshold for suspecting OA.

Ensure that continuing professional development on OA reaches those who are seeing working-age individuals with asthma, that is, respiratory-oriented GPs, practice nurses and advanced nurse practitioners.

Practice Promote and make asthma OA guidance accessible, either specifically or within generic asthma guidelines. Encourage dialogue between generalists and specialists on OA through mutual education and practice. Collect data useful for identifying OA, for example, work-related symptoms, job roles and any changes in employment or role.

Review local policies and pathways to ensure there is a secure pathway for referral for investigation of $O A$ and for specialist advice.

Incentivise healthcare professionals to make a diagnosis of OA by measuring health and employment outcomes rather than processes.

GP, general practitioner; OA, occupational asthma.

Funding Commercial typing costs and participant inducements were paid from the University Hospitals Birmingham NHS Foundation Trust Occupational Lung Disease Charity Fund

Competing interests Participant 1 was the wife of the primary author and a GP in a city centre practice.

Patient consent for publication Not required.

Ethics approval Formal NHS Research Ethics Committee review was not sought since the study did not involve patients. Health Research Authority approval for this study was granted on 16 July 2018 (IRAS reference number 249409).

Provenance and peer review Not commissioned; externally peer reviewed. Data availability statement Data are available upon reasonable request.

Supplemental material This content has been supplied by the author(s). It has not been vetted by BMJ Publishing Group Limited (BMJ) and may not have been peer-reviewed. Any opinions or recommendations discussed are solely those of the author(s) and are not endorsed by BMJ. BMJ disclaims all liability and responsibility arising from any reliance placed on the content. Where the content includes any translated material, BMJ does not warrant the accuracy and reliability of the translations (including but not limited to local regulations, clinical guidelines, terminology, drug names and drug dosages), and is not responsible for any error and/or omissions arising from translation and adaptation or otherwise.

Open access This is an open access article distributed in accordance with the Creative Commons Attribution Non Commercial (CC BY-NC 4.0) license, which permits others to distribute, remix, adapt, build upon this work non-commercially, and license their derivative works on different terms, provided the original work is properly cited, appropriate credit is given, any changes made indicated, and the use is non-commercial. See: http://creativecommons.org/licenses/by-nc/4.0/.

ORCID iD

Gareth I Walters http://orcid.org/0000-0002-7436-2261

\section{REFERENCES}

1 Blanc PD, Annesi-Maesano I, Balmes JR, et al. The occupational burden of nonmalignant respiratory diseases. An official American thoracic Society and European respiratory Society statement. Am J Respir Crit Care Med 2019;199:1312-34.

2 HSE. Work-Related asthma statistics in Great Britain, 2019. Available: https://www.hse.gov.uk/statistics/causdis/asthma.pdf [Accessed 28 Oct 2020].
3 Zhou AY, Seed M, Carder M, et al. Sentinel approach to detect emerging causes of work-related respiratory diseases. Occup Med 2020;70:52-9.

4 Ayres JG, Boyd R, Cowie H, et al. Costs of occupational asthma in the UK. Thorax 2011;66:128-33.

5 Vandenplas O, Dressel H, Wilken D, et al. Management of occupational asthma: cessation or reduction of exposure? A systematic review of available evidence. Eur Respir $J$ 2011;38:804-11.

6 Scottish Intercollegiate Guidelines Network/British Thoracic Society. British guideline on the management of asthma. London: BTS/ SIGN, 2019. https://www.brit-thoracic.org.uk/quality-improvement/ guidelines/asthma/

7 HSL. Group of occupational respiratory disease specialists (GORDS), 2020. Available: https://www.hsl.gov.uk/centreforworkpla cehealth/gords [Accessed 28th Oct 2020].

8 McNamee R, Carder M, Chen Y, et al. Measurement of trends in incidence of work-related skin and respiratory diseases, UK 19962005. Occup Environ Med 2008;65:808-14.

9 de Bono J, Hudsmith L. Occupational asthma: a community based study. Occup Med 1999;49:217-9.

10 Walters GI, McGrath EE, Ayres JG. Audit of the recording of occupational asthma in primary care. Occup Med 2012;62:570-3.

11 Nicholson PJ, Cullinan P, Burge PS. Occupational asthma: Prevention, identification \& management: Systematic review \& recommendations. London: British Occupational Health Research Foundation, 2010. http://www.bohrf.org.uk/projects/asthma.html

12 Fishwick D, Bradshaw L, Davies J, et al. Are we failing workers with symptoms suggestive of occupational asthma? Prim Care Respir J 2007:16:304-10.

13 Bradshaw LM, Barber CM, Davies J, et al. Work-Related asthma symptoms and attitudes to the workplace. Occup Med 2007;57:30-5.

14 Walters GI, Soundy A, Robertson AS, et al. Understanding health beliefs and behaviour in workers with suspected occupational asthma. Respir Med 2015;109:379-88.

15 Barber CM, Frank T, Walsh K, et al. Knowledge and utilisation of occupational asthma guidelines in primary care. Prim Care Respir J 2010;19:274-80

16 Poonai N, van Diepen S, Bharatha A, et al. Barriers to diagnosis of occupational asthma in Ontario. Can J Public Health 2005;96:230-3

17 Parhar A, Lemiere C, Beach JR. Barriers to the recognition and reporting of occupational asthma by Canadian pulmonologists. Can Respir J 2011;18:90-6. 
18 Holness DL, Tabassum S, Tarlo SM, et al. Practice patterns of pulmonologists and family physicians for occupational asthma. Chest 2007;132:1526-31.

19 O'Brien BC, Harris IB, Beckman TJ, et al. Standards for reporting qualitative research: a synthesis of recommendations. Acad Med 2014;89:1245-51.

20 Green J, Thorogood N. Qualitative methods for health research. 3rd edition. London: Sage, 2014: 122.

21 Melia K. Conducting an interview. Nurse Res 2000;7:75-89.

22 Soundy A, Benson J, Dawes H. Adjustment and hope in individuals with multiple sclerosis. Physiotherapy 2012;98:349-55.

23 Braun V, Clarke V. Using thematic analysis in psychology. Qual Res Psychol 2006;3:77-101.
24 Maguire M, Delahunt B. Doing a thematic analysis: a practical, step-by-step guide for learning and teaching scholars. AISHE-J 2017;3.

25 MacKinnon M, To T, Ramsey C, et al. Improving detection of work-related asthma: a review of gaps in awareness, reporting and knowledge translation. Allergy Asthma Clin Immunol 2020;16:73.

26 Ellis PR, Walters Gl. Missed opportunities to identify occupational asthma in acute secondary care. Occup Med 2018;68:56-9.

27 Mackie J. Effective health surveillance for occupational asthma in motor vehicle repair. Occup Med 2008;58:551-5.

28 Walters Gl, Burge PS, Sahal A, et al. Hospital attendances and acute admissions preceding a diagnosis of occupational asthma. Lung 2019;197:613-6. 